\title{
A Compact UWB Diversity Antenna
}

\author{
Hui Zhao, ${ }^{1,2}$ Fushun Zhang, ${ }^{1}$ Chunyang Wang, ${ }^{2}$ and Jiangang Liang ${ }^{2}$ \\ ${ }^{1}$ National Key Laboratory of Antennas and Microwave Technology, Xidian University, Xian, Shaanxi 710071, China \\ ${ }^{2}$ Missile Institute of Air Force Engineering University, Sanyuan, Shaanxi 713800, China \\ Correspondence should be addressed to Hui Zhao; microwave_zhao@163.com
}

Received 5 May 2013; Accepted 16 December 2013; Published 9 January 2014

Academic Editor: Alistair P. Duffy

Copyright (C) 2014 Hui Zhao et al. This is an open access article distributed under the Creative Commons Attribution License, which permits unrestricted use, distribution, and reproduction in any medium, provided the original work is properly cited.

\begin{abstract}
A compact printed ultrawideband (UWB) diversity antenna with a size of $30 \mathrm{~mm} \times 36 \mathrm{~mm}$ operating at a frequency range of $3.1-$ $10.6 \mathrm{GHz}$ is proposed. The antenna is composed of two semielliptical monopoles fed by two microstrip lines. Two semicircular slots, two rectangular slots, and one stub are introduced in the ground plane to adjust the impedance bandwidth of the antenna and improve the isolation between two feeding ports. The simulated and measured results show that impedance bandwidth of the proposed antenna can cover the whole UWB band with a good isolation of $<-15 \mathrm{~dB}$. The radiation patterns, peak antenna gain, and envelope correlation coefficient are also measured and discussed. The measured results show that the proposed antenna can be a good candidate for some portable MIMO/diversity UWB applications.
\end{abstract}

\section{Introduction}

Ultrawideband (UWB) communication systems attract great attention in the wireless world because of their advantages, including high speed data rate, extremely low spectral power density, high precision ranging, low cost, and low complexity, since the Federal Communication Commission (FCC) allowed 3.1-10.6 GHz unlicensed band for UWB communication [1]. Multiple input and output (MIMO) antennas used in UWB systems can improve systems' performance such as providing increased data rates and making increased range available through beam forming [2]. Antenna diversity is a well-known technique to enhance the performance of MIMO systems by mitigating the multipath fading and cochannel interference [3-5]. Thus, a MIMO/diversity antenna covering UWB band and having good radiation patterns and diversity performance has become the focus of wireless communications [6-10]. However, the operating frequency of the antennas in [6-10] cannot cover the whole band of 3.1$10.6 \mathrm{GHz}$ and the size of the antenna in $[6-8]$ is relatively large. Recently, an UWB diversity antenna covering the whole UWB and having a small size has been presented in [11]. The proposed antenna has a size of $35 \mathrm{~mm} \times 40 \mathrm{~mm}$, and a good isolation better than $-16 \mathrm{~dB}$ has been achieved through a tree-like structure introduced in the ground plane. However, the size of the antenna in [11] is still relatively large and a complicate tree-like structure should be designed to weaken the mutual coupling between two monopoles due to the close distance between them.

In this paper, we propose a simple MIMO/diversity antenna covering the whole UWB band and having a small size of $30 \mathrm{~mm} \times 36 \mathrm{~mm}$ which is only 75 percent of the antenna in [11]. The proposed antenna is designed by using two semielliptical monopoles. By properly adjusting the distance between two monopoles and introducing two semicircular slots, two rectangular slots, and one stub in the ground plane, the antenna can achieve a broad impedance bandwidth covering the whole UWB with good isolation of $<-15 \mathrm{~dB}$.

\section{Antenna Configuration and Analysis}

2.1. Antenna Configuration. The specific geometry with detailed dimensions of the proposed antenna is illustrated in Figure 1(a), and the photograph of the proposed antenna is shown in Figure 1(b). The antenna consists of dual semielliptical monopoles which are aligned along $y$-axis with an optimized distance of $15.3 \mathrm{~mm}$ which is about a quarter 


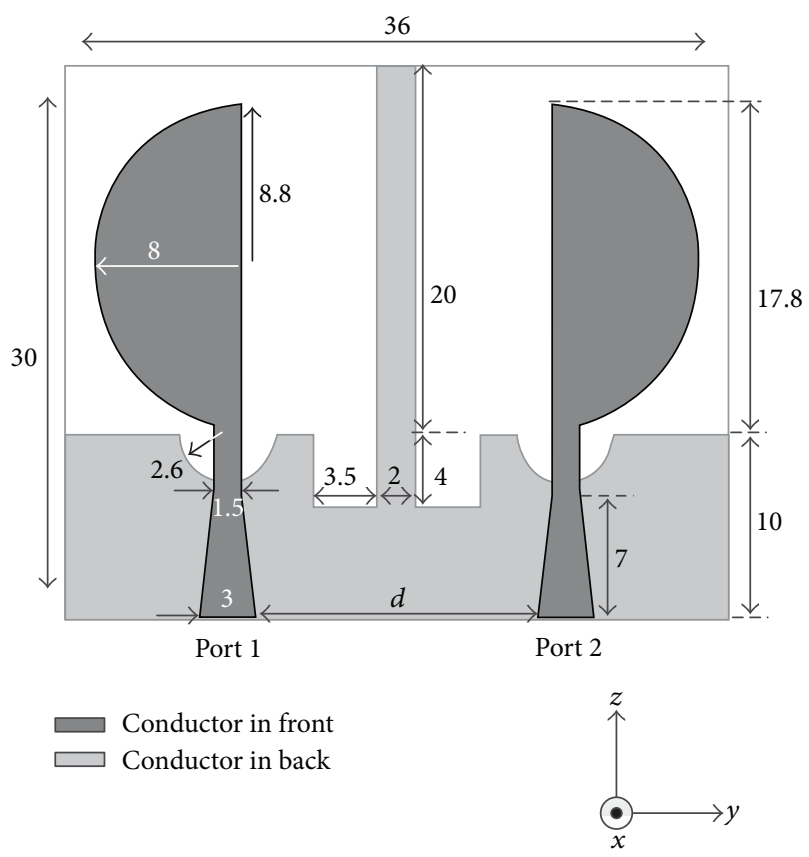

(a)

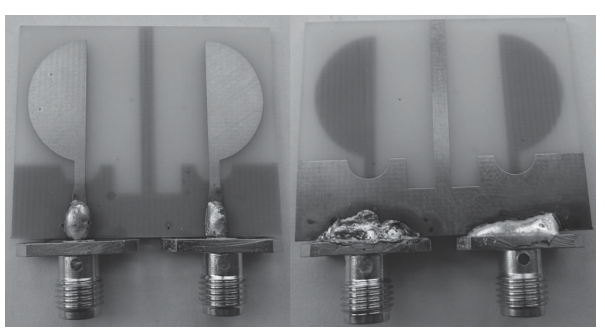

(b)

Figure 1: Geometry and photograph of the proposed antenna $(d=15.3$, dimensions, $\mathrm{mm})$.

guided wavelengths at $3 \mathrm{GHz}$. The guided wavelengths $\lambda_{g}$ can be calculated by using

$$
\lambda_{g}=\frac{c}{f \sqrt{\left(\varepsilon_{r}+1\right) / 2}}
$$

where $f$ is the frequency, $\varepsilon_{r}$ and $\sqrt{\left(\varepsilon_{r}+1\right) / 2}$ are the relative permittivity and effective permittivity of the substrate, respectively, and $c$ is the speed of light. The major radius and the radius ratio of the semielliptical monopole are $8 \mathrm{~mm}$ and 1.1, respectively. Each monopole is fed by a $50 \Omega$ tapered microstrip line with an upper width of $1.5 \mathrm{~mm}$, lower width of $3 \mathrm{~mm}$, and height of $7 \mathrm{~mm}$. The monopoles are printed on the upper part of a partially grounded FR4 substrate with dimensions $30 \mathrm{~mm} \times 36 \mathrm{~mm} \times 1.6 \mathrm{~mm}$ and relative permittivity 4.6. On the back surface of the substrate, the main rectangular ground plane of $36 \mathrm{~mm}$ in width and $10 \mathrm{~mm}$ in length is printed. Note that two semicircular slots with same radius of $2.6 \mathrm{~mm}$, one stub of $2 \mathrm{~mm}$ in width, and $20 \mathrm{~mm}$ in length in the middle of the ground plane and two rectangular slots of $3.5 \mathrm{~mm}$ in width and $4 \mathrm{~mm}$ in length at the bottom of the stub are introduced in the ground plane to adjust the impedance bandwidth of the antenna and improve the isolation between two feeding ports.

2.2. Antenna Analysis. By aligning two semielliptical monopoles along $y$-axis with a proper distance between them and introducing two semicircular slots, one stub, and two rectangular slots in the ground plane in turn, the proposed antenna can be designed conventionally.

To well understand the design mechanisms of the proposed antenna, the scattering parameters of the proposed antenna with or without the slots and stub are simulated by using High-Frequency Structure Simulation (HFSS), Version-12, software. Due to the symmetrical structure of the proposed antenna, only the reflection coefficient $\left|S_{11}\right|$ at port 1 and isolation $\left|S_{21}\right|$ between two feeding ports are simulated. The simulated results are shown in Figure 2.

As shown in Figure 2(a), one can observe that the impedance bandwidth of the proposed antenna without all slots and stub tends to cover the whole UWB band, and the isolation between two feeding ports is very poor. In order to enhance or adjust the impedance bandwidth of the antenna, dual semicircular slots with a radius of $2.6 \mathrm{~mm}$ are introduced in the ground plane and the simulation results are shown in Figure 2(b). The slots in the ground plane are achieved to obtain the necessary interaction between this plane and the radiator so that the proper matching impedance is received. It can be observed from Figure 2(b) that the impedance bandwidth of the antenna is enhanced and can cover the whole UWB but a poor isolation is still achieved especially in the upper band. To improve the isolation between two feeding ports, a stub of $2 \mathrm{~mm}$ in width and $20 \mathrm{~mm}$ in length in the middle of the ground plane is introduced and the simulation results are shown in Figure 2(c). The stub can be viewed as a reflector to reduce the mutual coupling through separating the radiation patterns of two radiators. As shown in Figure 2(c), it can be observed that a high isolation is achieved by introducing the stub in the ground plane. However, the impedance bandwidth of the antenna around the 7 to $9 \mathrm{GHz}$ region is mismatched, and the isolation around the 9 to $10.6 \mathrm{GHz}$ region is still a little poor. Thus, two rectangular slots of $3.5 \mathrm{~mm}$ in width and $4 \mathrm{~mm}$ in length at the bottom of the stub are introduced in the ground plane. 


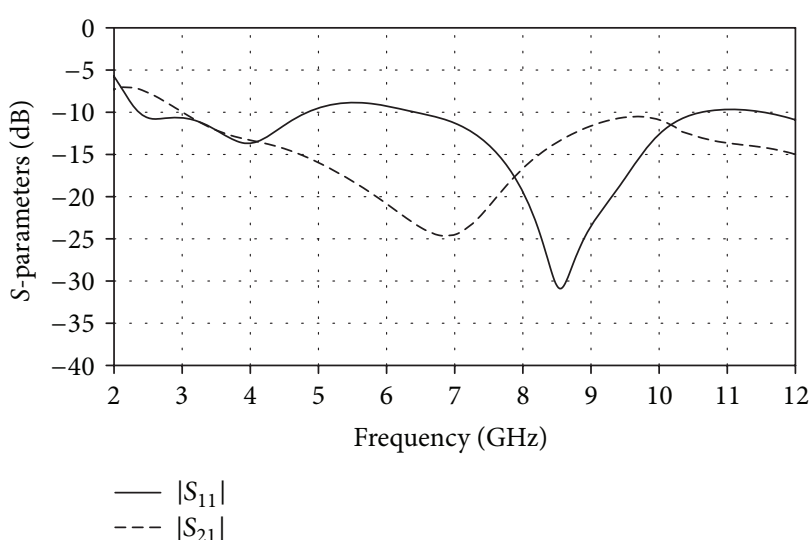

(a)

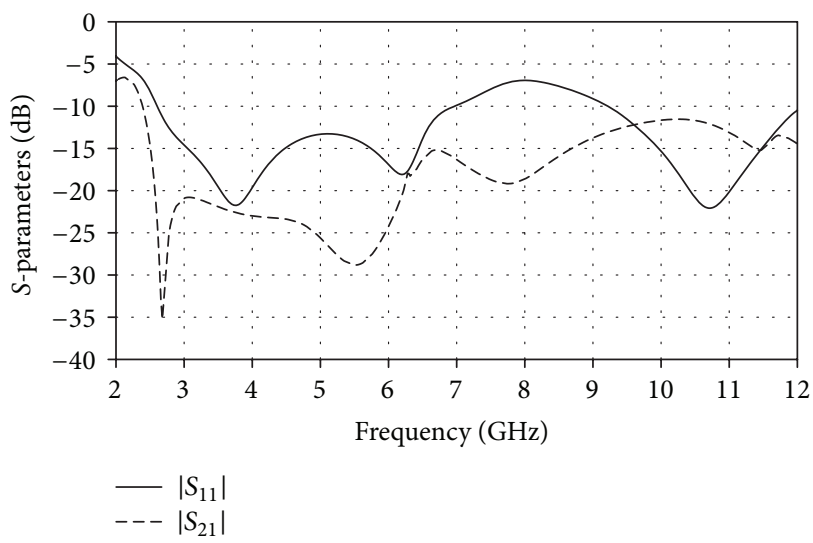

(c)

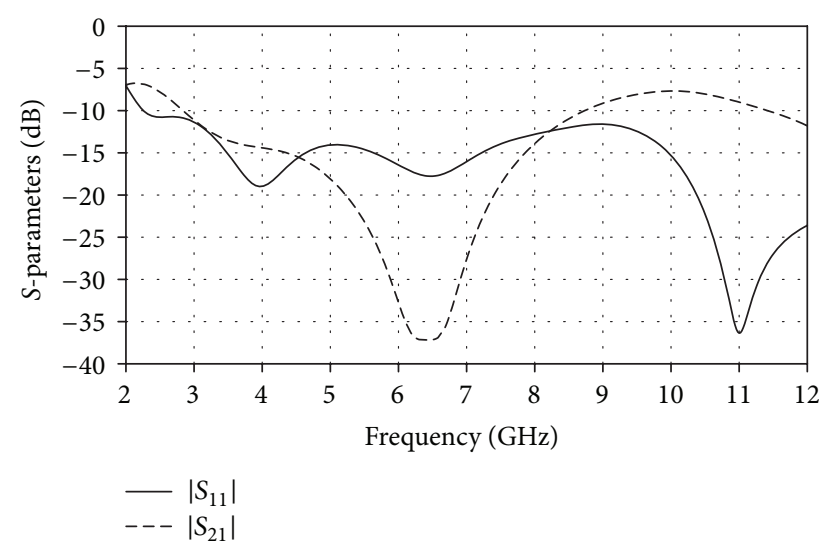

(b)

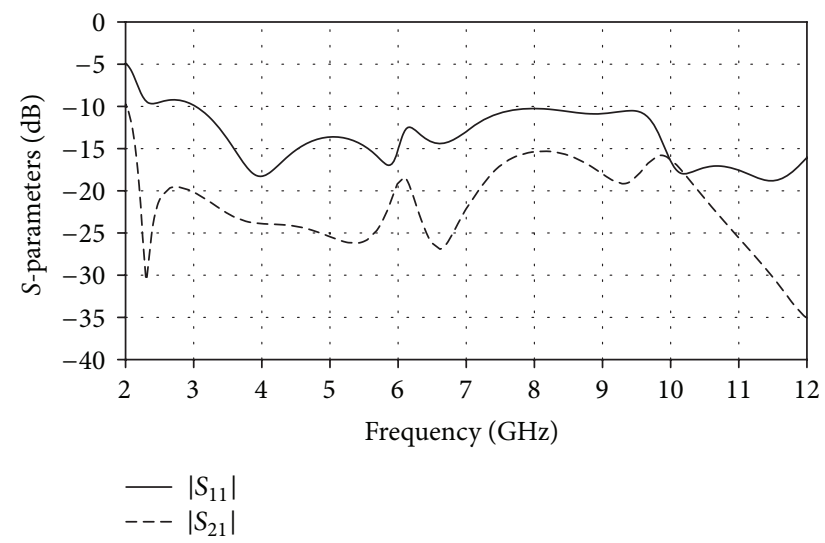

(d)

FIGURE 2: Simulated reflection coefficient $\left|S_{11}\right|$ and isolation $\left|S_{21}\right|$ against frequency of the proposed antenna: (a) without all of the slots and the stub in the ground plane, (b) without two rectangular slots and the stub in the ground plane, (c) without the stub in the ground plane, and (d) with all of the slots and the stub in the ground plane, that is, the proposed antenna.

The rectangular slots in the ground plane are achieved to not only obtain the necessary interaction between ground plane and the radiators but also adjust the length of the stub so that the proper matching impedance and a good isolation are received. The simulation results of the proposed antenna are shown in Figure 2(d); one can observe that a broad impedance bandwidth covering the whole UWB with good isolation of $<-15 \mathrm{~dB}$ is achieved.

Additionally, the influence of the distance between two feeding lines on the performance of the proposed antenna is also simulated and the simulated results are shown in Figure 3. It can be seen that by increasing or decreasing the distance between feeding lines the isolation can be improved or weakened as shown in Figure 3(b), and the impedance bandwidth cannot cover the whole UWB with too far or too close distance between the monopoles as shown in Figure 3(a). Therefore, the distance between the monopoles should be optimized with attention to the impedance bandwidth and isolation.

Furthermore, unlike the antenna in [11], in our design two semielliptical monopoles are aligned along $y$-axis back-toback as shown in Figure 1; the advantage of this configuration is that the minimum distance between the monopoles is almost equal to the distance between two feeding lines, therefore, a more complicate structure such as a tree-like one [11] to improve the isolation is not necessary in the design; that is, fewer parameters need to be optimized and the antenna can be designed simply.

\section{Experimental Results and Discussion}

Based upon the design dimensions shown in Figure 1, the proposed UWB MIMO/diversity antenna was constructed, measured, and analysed as follows.

3.1. Input Characteristic. Figure 4 shows the measured reflection coefficient $\left|S_{11}\right|$ and isolation $\left|S_{21}\right|$ against frequency of the proposed antenna. Note that, due to the symmetric structures of the proposed antenna, the measured $\left|S_{22}\right|$ is almost the same as $\left|S_{11}\right|$ and is thus not shown in the figure for the sake of brevity. It can be observed from Figure 4 that the obtained impedance bandwidth defined by $\left|S_{11}\right|<-10 \mathrm{~dB}$ can cover the whole UWB of 3.1-10.6 GHz. In addition, across the whole UWB, a good isolation between two feeding ports is obtained $\left(\left|S_{21}\right|<-15 \mathrm{~dB}\right)$. 


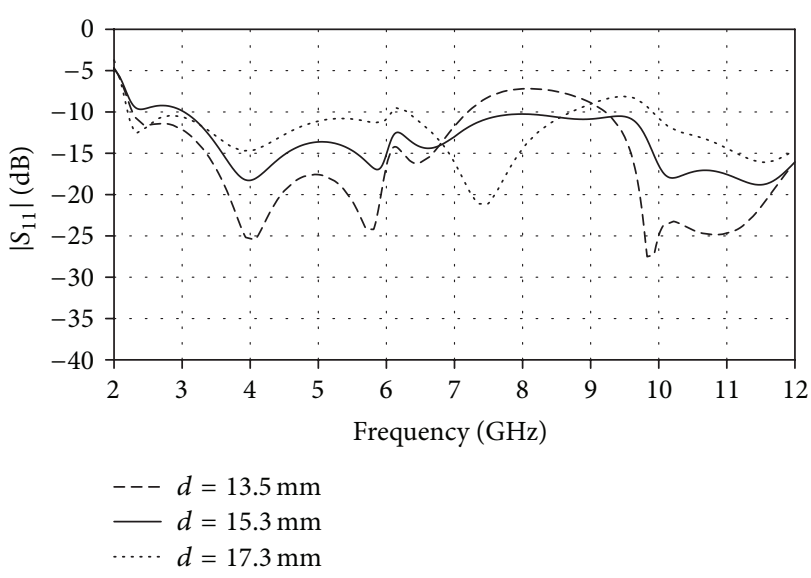

(a)

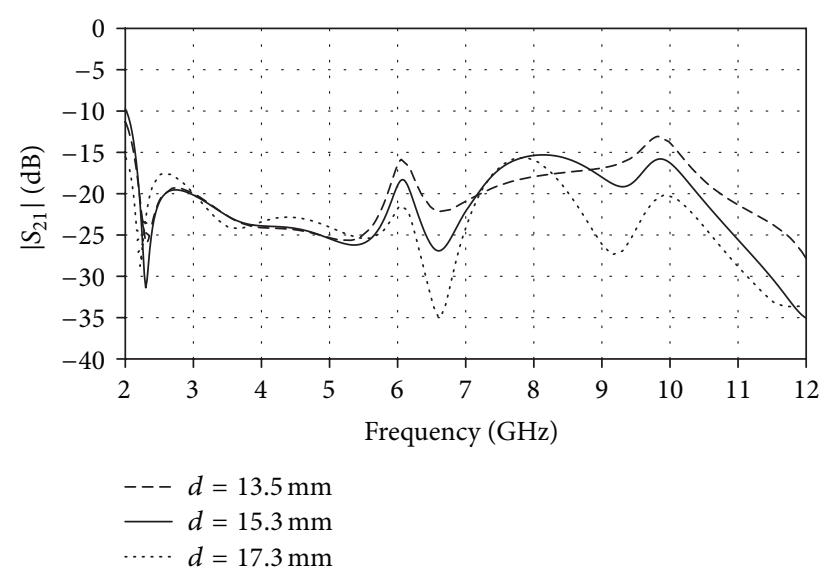

(b)

FIGURE 3: Simulated $S$-parameters against frequency of the proposed antenna with different $d$ : (a) reflection coefficient $\left|S_{11}\right|$ and (b) isolation $\left|S_{21}\right|$.

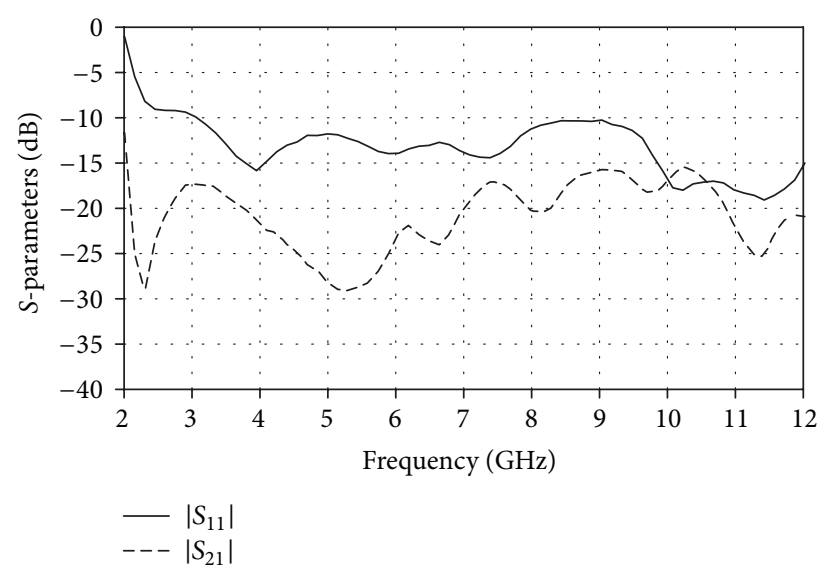

FIGURE 4: Measured reflection coefficient $\left|S_{11}\right|$ and isolation $\left|S_{21}\right|$ against frequency of the proposed antenna.

3.2. Radiation Patterns. The radiation patterns at 4,7 , and $10 \mathrm{GHz}$ of the proposed antenna were measured in an anechoic chamber. Figure 5 plots the radiation patterns for the proposed antenna on the $x-z$ ( $E$-plane), $x-y$ ( $H$-plane) plane, and $y-z$ plane with port 1 excited and port 2 connected to a $50 \Omega$ load. As shown in Figure 5 , the radiation patterns of the proposed antenna are relatively stable across the UWB. In addition, due to the symmetric structures of two monopoles, when port 2 is excited, with port 1 terminated, the patterns in the $x-z$ plane are similar to those in Figure 5, but the patterns in the $x-y$ and $y-z$ planes are mirror transformations about $x-z$ plane of those in Figure 5. In other words, the radiation patterns tend to cover complementary space regions, which provide spatial diversity for the system operation to overcome the multipath fading problem and enhance the system's performance.

The measured peak antenna gain for port 1 excitation is shown in Figure 6. Due to the symmetric structures of two monopoles, the measured peak antenna gain for port 2 excitation is about the same and not shown in the figure. The result shows a gain level of about $6.9 \mathrm{dBi}$, with gain variations less than $3.9 \mathrm{dBi}$ across the operating band.

3.3. Diversity Performance. A diversity antenna is characterised by the individual antenna gain and the overall diversity gain. Diversity gain could be calculated using the analysis in [12-14]. The measured far field radiation pattern can be used for calculating the envelope correlations of the proposed antenna using [15]

$$
\rho_{e}=\frac{A}{B C}
$$

where

$$
\begin{aligned}
A=(\oint & \left(\mathrm{XPRE}_{\theta 1}(\Omega) E_{\theta 2}^{*}(\Omega) P_{\theta}(\Omega)\right. \\
& \left.\left.+E_{\varphi 1}(\Omega) E_{\varphi 2}^{*}(\Omega) P_{\varphi}(\Omega)\right) d(\Omega)\right)^{2},
\end{aligned}
$$




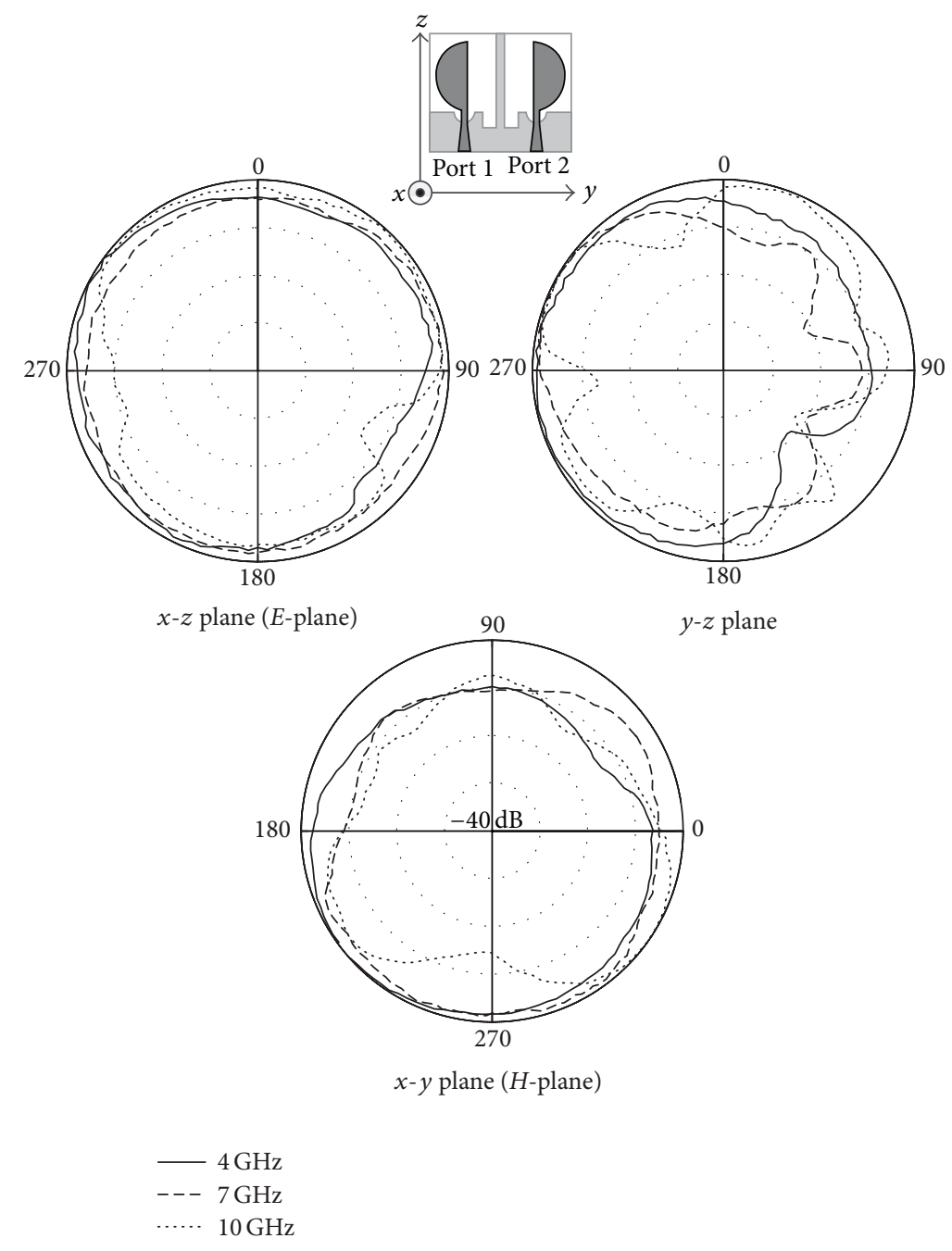

FIGURE 5: Measured radiation patterns of the proposed antenna.

$$
\begin{gathered}
B=\oint\left(\operatorname{XPR}_{\theta 1}(\Omega) P_{\theta}(\Omega)+G_{\varphi 1}(\Omega) P_{\varphi}(\Omega)\right) d(\Omega), \\
C=\oint\left(\operatorname{XPR}_{\theta 2}(\Omega) P_{\theta}(\Omega)+G_{\varphi 2}(\Omega) P_{\varphi}(\Omega)\right) d(\Omega), \\
G_{\theta}=E_{\theta}(\Omega) * E_{\theta}^{*}(\Omega), \\
\Omega=(\theta, \varphi) .
\end{gathered}
$$

$E_{\theta 1}(\Omega), E_{\theta 2}(\Omega), E_{\varphi 1}(\Omega), E_{\varphi 2},(\Omega)$, and $P_{\theta, \varphi}(\Omega)$ are, respectively, the vertical $(\theta)$ and horizontal $(\varphi)$ polarized complex patterns of the two semielliptical monopoles and the incident power spectrum of the different polarizations. Crosspolar discrimination (XPR) is the time-averaged vertical-tohorizontal power ratio.

The diversity gain at $1 \%$ of the cumulative distribution functions and envelope correlation coefficient for the proposed UWB MIMO/diversity antenna is larger than $9.6 \mathrm{~dB}$ and below $-17 \mathrm{~dB}$, respectively, across the whole UWB of 3.1$10.6 \mathrm{GHz}$. These results indicate that the proposed antenna has a good diversity performance and can be a good candidate for an UWB system.

\section{Conclusions}

An UWB MIMO/diversity monopole antenna has been presented. The antenna has a more compact size than the antennas presented in the existing literature. The obtained operating bandwidth of the proposed antenna can cover the whole UWB of 3.1 to $10.6 \mathrm{GHz}$. Across the UWB, the antenna also shows good port isolation and stable radiation pattern, and can provide spatial diversity to combat the multipath fading problem. Thus, the proposed antenna is suitable for some portable UWB MIMO/diversity applications.

\section{Conflict of Interests}

The authors declare that there is no conflict of interests regarding the publication of the paper. 


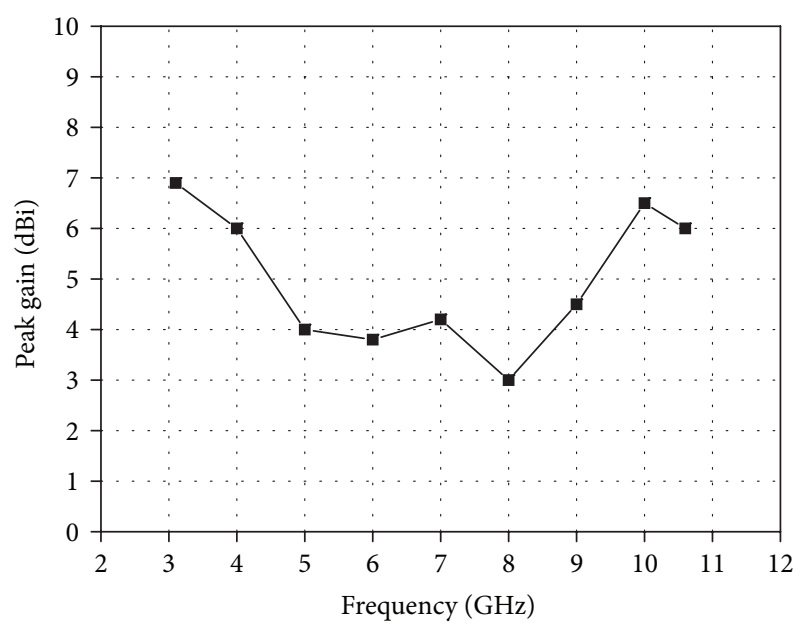

FIGURE 6: Measured peak antenna gain across the UWB for port 1 excitation.

\section{Acknowledgment}

The authors should deliver their sincere gratitude to the anonymous reviewers for their constructive comments which have made the authors' much better than before.

\section{References}

[1] "First report and order in the matter of Revision of Part 15 of the commission's rules regarding ultra-wideband transmission systems," Federal Communications Commission, ET-Docket 98-153, 2002.

[2] T. Kaiser, F. Zheng, and E. Dimitrov, "An overview of ultra-wideband systems with MIMO," Proceedings of the IEEE, vol. 97, no. 2, pp. 285-312, 2009.

[3] B. Yu, C. W. Jung, H. Lee et al., "Closely mounted compact wideband diversity antenna for mobile phone applications," International Journal of Antennas and Propagation, vol. 2012, Article ID 798046, 6 pages, 2012.

[4] J. F. Zheng, Y. Li, and Z. H. Feng, "Impact of mutual coupling and polarization of antennas on BER performances of spatial multiplexing MIMO systems," International Journal of Antennas and Propagation, vol. 2012, Article ID 795205, 12 pages, 2012.

[5] R. G. Vaughan and J. B. Andersen, "Antenna diversity in mobile communications," IEEE Transactions on Vehicular Technology, vol. 36, no. 4, pp. 149-172, 1987.

[6] K.-L. Wong, S.-W. Su, and Y.-L. Kuo, "A printed ultra-wideband diversity monopole antenna," Microwave and Optical Technology Letters, vol. 38, no. 4, pp. 257-259, 2003.

[7] L. Liu, H. Zhao, T. S. P. See, and Z. N. Chen, "A printed ultra-wideband diversity antenna," in Proceedings of the IEEE International Conference on Ultra-Wideband (ICUWB '06), pp. 351-356, Waltham, Mass, USA, September 2006.

[8] S. Hong, K. Chung, J. Lee, S. Jung, S.-S. Lee, and J. Choi, "Design of a diversity antenna with stubs for UWB applications," Microwave and Optical Technology Letters, vol. 50, no. 5, pp. 1352-1356, 2008.

[9] T. S. P. See and Z. N. Chen, "An ultrawideband diversity antenna," IEEE Transactions on Antennas and Propagation, vol. 57, no. 6, pp. 1597-1605, 2009.
[10] W. K. Toh, Z. N. Chen, X. Qing, and T. S. P. See, "A planar UWB diversity antenna," IEEE Transactions on Antennas and Propagation, vol. 57, no. 11, pp. 3467-3473, 2009.

[11] S. Zhang, Z. Ying, J. Xiong, and S. He, "Ultrawideband $\mathrm{MIMO} /$ diversity antennas with a tree-like structure to enhance wideband isolation," IEEE Antennas and Wireless Propagation Letters, vol. 8, pp. 1279-1282, 2009.

[12] M. Karaboikis, V. Papamichael, C. Soras, and V. Makios, "A multiband diversity antenna system for compact mobile/wireless devices: modeling and performance evaluation," International Journal of Antennas and Propagation, vol. 2008, Article ID 782153, 7 pages, 2008.

[13] P.-S. Kildal and K. Rosengren, "Electromagnetic analysis of effective and apparent diversity gain of two parallel dipoles," IEEE Antennas and Wireless Propagation Letters, vol. 2, pp. 913, 2003.

[14] S. Blanch, J. Romeu, and I. Corbella, "Exact representation of antenna system diversity performance from input parameter description," Electronics Letters, vol. 39, no. 9, pp. 705-707, 2003.

[15] R. Addaci, A. Diallo, C. Luxey, P. le Thuc, and R. Staraj, "Dualband WLAN diversity antenna system with high port-to-port isolation," IEEE Antennas and Wireless Propagation Letters, vol. 11, pp. 244-247, 2012. 

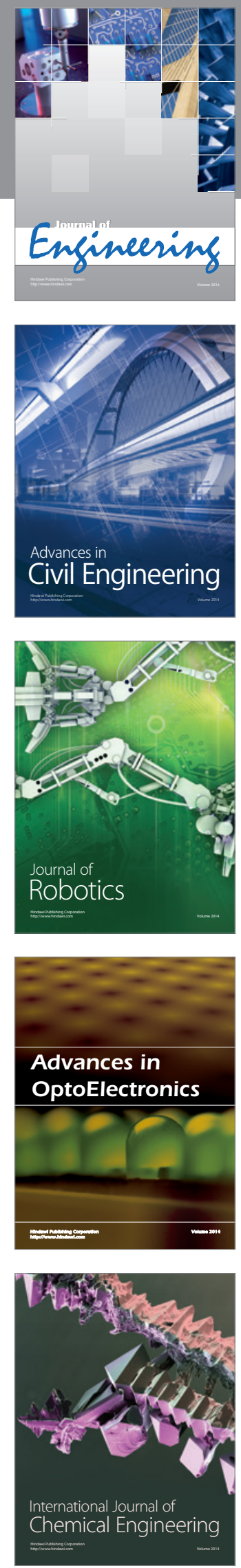

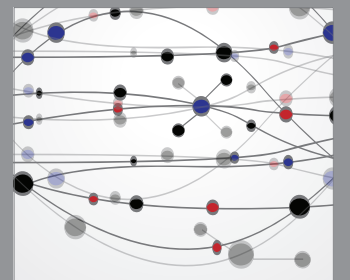

The Scientific World Journal
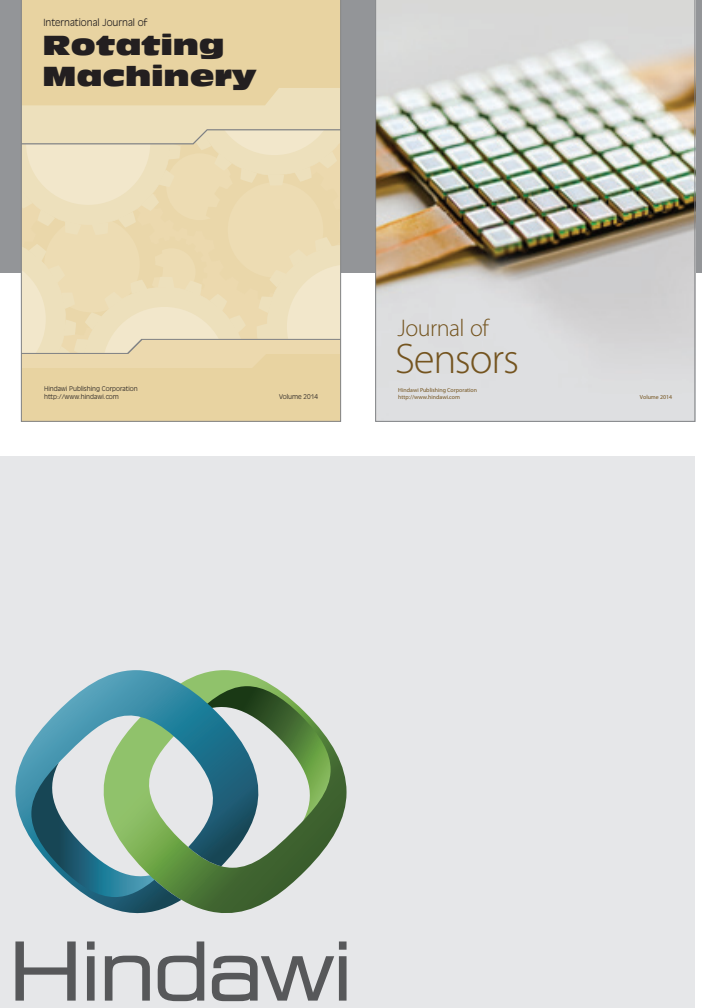

Submit your manuscripts at http://www.hindawi.com
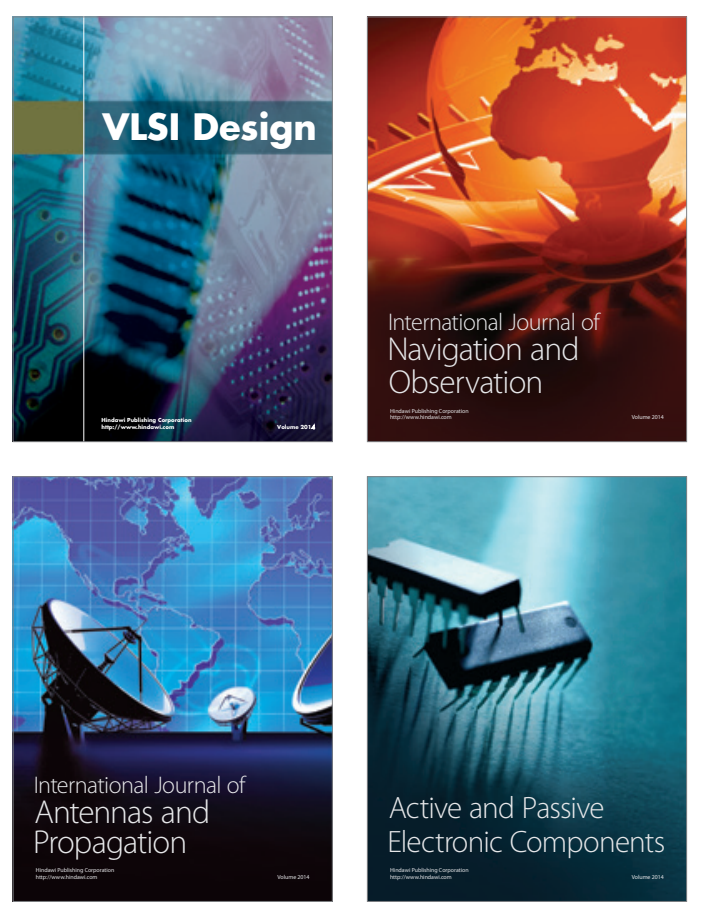
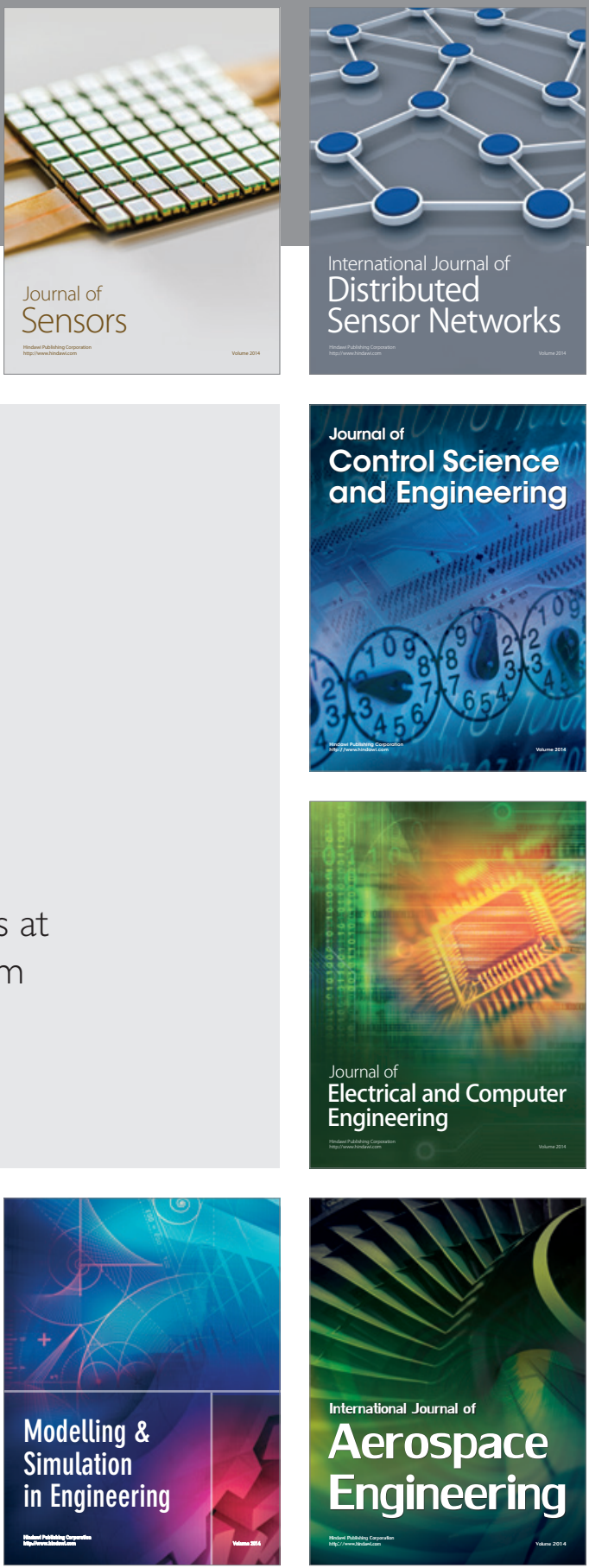

Journal of

Control Science

and Engineering
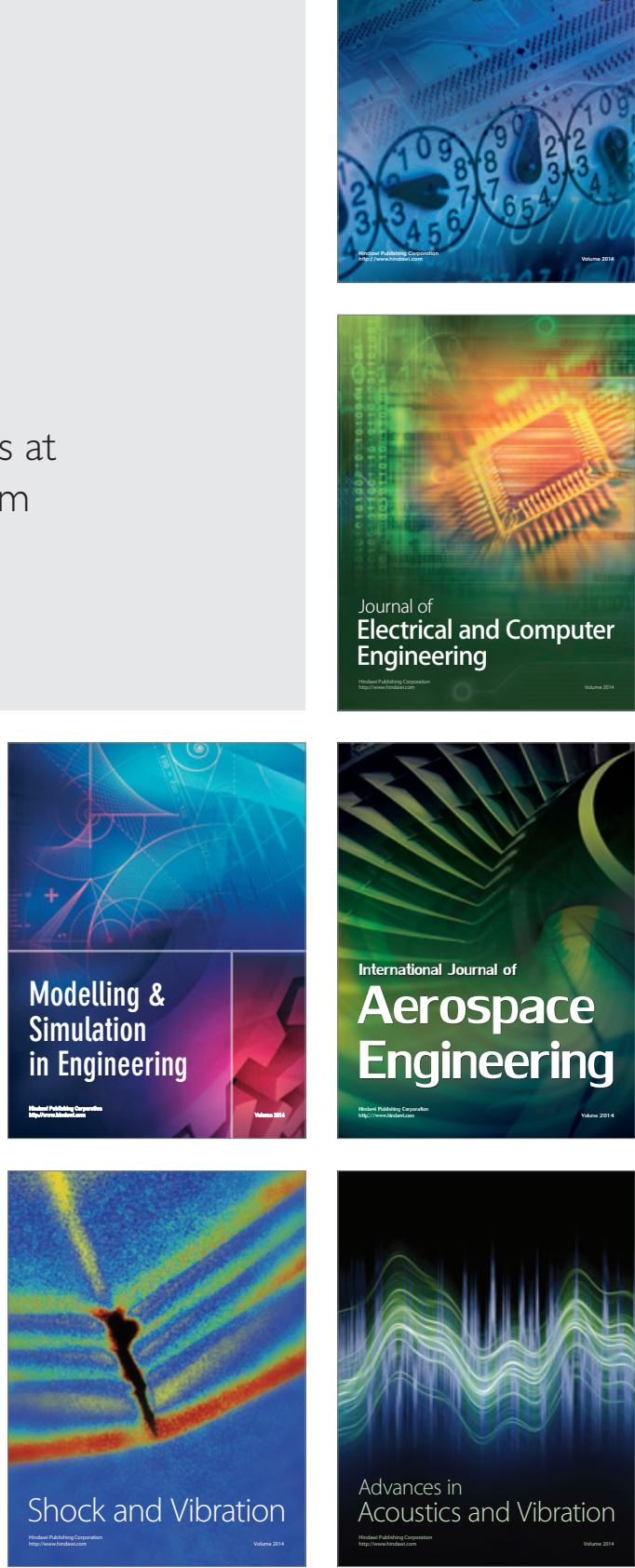